\title{
Association of Helicobacter pylori infection with metabolic syndrome in aged Chinese females
}

\author{
YINGYING YU ${ }^{1}$, JIANTING CAI ${ }^{2}$, ZHENYA SONG $^{1}$, JINGHUA WANG ${ }^{1}$ and LINGYAN WU ${ }^{1}$ \\ Departments of ${ }^{1}$ General Practice and ${ }^{2}$ Gastroenterology, The Second Affiliated Hospital, \\ Zhejiang University School of Medicine, Hangzhou, Zhejiang 310000, P.R. China
}

Received October 22, 2018; Accepted March 13, 2019

DOI: $10.3892 /$ etm.2019.7509

\begin{abstract}
The association between Helicobacter pylori (H. pylori) infection and metabolic syndrome (MetS) determined in different cohorts from different countries is currently inconclusive. In the majority of previous studies, $H$. pylori infection was diagnosed based on the presence of H. pylori $\mathrm{IgG}$ antibody in the serum. However, to the best of our knowledge, only few studies have investigated the association between $H$. pylori infection and MetS using the urea breath test (UBT) as a diagnostic tool. The present study was performed with the aim of providing a detailed analysis of the association between $H$. pylori infection, as diagnosed by the UBT method, and MetS in a large community from Zhejiang province in eastern China. The results indicated that $H$.pylori infection increases the risk of MetS in the aged female population.
\end{abstract}

\section{Introduction}

Metabolic syndrome (MetS) comprises a group of metabolic abnormalities, including central obesity, impaired glucose tolerance, insulin resistance (IR), lipid metabolism disorders and hypertension, which markedly increase the risk of

Correspondence to: Dr Jianting Cai, Department of Gastroenterology, The Second Affiliated Hospital, Zhejiang University School of Medicine, 88 Jiefang Road, Hangzhou, Zhejiang 310009, P.R. China

E-mail:dleowa@zju.edu.cn

Abbreviations: H. pylori, Helicobacter pylori, MetS, metabolic syndrome; BMI, body mass index; WBC, white blood cell; Hb, hemoglobin; ALT, alanine aminotransferase; AST, aspartate aminotransferase; $\mathrm{Cr}$, creatinine; UA, uric acid; HCY, homocysteic acid; CYSC, serum cystatin C; HS-CRP, high-sensitivity C-reactive protein; HbAlc, glycosylated Hb; HOMA-IR, homeostasis model assessment of insulin resistance; HDL-C, high-density lipoprotein cholesterol; TG, triglyceride; 95\% CI, 95\% confidence interval; OR, odds ratio

Key words: Helicobacter pylori, metabolic syndrome, insulin resistance, 13C-urea breath test, Chinese aged women diabetes mellitus and cardio-cerebrovascular disease (1-3). Approximately one-quarter of the population worldwide have been reported to suffer from MetS (2). Chronic inflammation was previously suggested to be implicated in MetS (4).

Helicobacter pylori (H. pylori) infection is one of the most common infections globally, affecting $>50 \%$ of the world's population, particularly in developing countries. Its prevalence varies across different cohorts with differences in age and developmental status $(5,6)$. H. pylori infection may cause chronic gastritis, peptic ulcers and gastric cancer (7-9). More recently, $H$. pylori gastritis was considered as an infectious disease (10). H. pylori infection has been indicated to increase systemic inflammation by producing inflammatory factors, including C-reactive protein (CRP), tumor necrosis factor- $\alpha$, interferon- $\gamma$ and interleukin-1, -6 and -8 , and these factors were confirmed to be involved in the pathogenesis of IR $(11,12)$. In addition to gastrointestinal infections, $H$. pylori has also been reported to be associated with various extra-intestinal diseases, including MetS (13-20).

At present, the association between $H$. pylori infection and MetS determined in different cohorts of different countries remains inconclusive (17,20-32). In the majority of those studies, $H$. pylori infection was diagnosed based on the presence of $H$. pylori IgG antibody in the serum (29-31); however, serum IgG may persist after $H$. pylori is eradicated and may therefore not reflect the current infection status (33). The ${ }^{13} \mathrm{C}$-urea breath test (UBT) is a non-invasive method for detecting current $H$. pylori infection. The sensitivity and specificity of the UBT are $\sim 0.96$ [95\% confidence interval (CI): 0.95-0.97] and 0.93 (95\% CI: 0.91-0.94), respectively (34). While it may be assumed that only current infection is able to cause systemic inflammatory reactions, few studies have investigated the association between $H$. pylori infection and MetS using UBT as the diagnostic method, to the best of our knowledge.

Therefore, given the diversity of the incidence of $H$. pylori infection across different countries and the controversial results of the studies investigating the association between $H$. pylori infection and MetS, particularly in East Asia, it is crucial to further investigate this association in a large population. The aim of the present study was to provide a detailed analysis of the association between $H$. pylori infection, as diagnosed by UBT, and MetS in a large community from Zhejiang province in eastern China. 


\section{Materials and methods}

Study participants. Participants who voluntarily underwent a general health screening between January 2014 and December 2015 were recruited at the International Health Care Center of the Second Affiliated Hospital of Zhejiang University School of Medicine (Hangzhou, China). Participants with any of the following characteristics were excluded from the study: i) History of gastric surgery; ii) history of anti-H. pylori therapy; iii) use of antibiotics, proton pump inhibitors, $\mathrm{H} 2$ blockers or bismuth within the previous 4 weeks; iv) severe mental or neurological disorders; v) history of cancer(s). All subjects underwent a detailed physical examination, including UBT detection of $H$. pylori infection.

Diagnosis of H. pylori infection. After fasting for at least $2 \mathrm{~h}$, all of the participants underwent a ${ }^{13} \mathrm{C}-\mathrm{UBT}$ (Richen-Force, Beijing, China) for the detection of $H$. pylori infection. After collecting the baseline breath sample, the participants ingested $\mathrm{a}^{13} \mathrm{C}$-urea reagent dissolved in water. The second breath sample was collected and analyzed after $30 \mathrm{~min}$. A delta over baseline value $\geq 4.0$ indicated a positive result for $H$. pylori infection.

Definitions of the study variables. For each participant, age, sex, weight, height, body mass index (BMI) and waist circumference were recorded. Blood pressure was measured after at least $10 \mathrm{~min}$ of rest. Waist circumference was measured with a measuring tape while standing, midway between the lowest rib and the iliac crest. The BMI was calculated as follows: Weight $(\mathrm{kg}) /[\text { height }(\mathrm{m})]^{2}$.

Information on the history of smoking and alcohol consumption, as well as the medical history, including hypertension, hyperlipidemia and/or diabetes, was also collected using a questionnaire. The questionnaire also included the history of the present illness, previous diagnoses of $H$. pylori infection, history of anti-H. pylori therapy and confirmation of eradication after treatment. If the questionnaire was incomplete, the patient was contacted to ensure for integrity of the data.

Laboratory examinations were performed after a 10 -h fast, including white blood cell (WBC) count, hemoglobin (Hb), platelet count, high-sensitivity (HS)-CRP, total cholesterol, low-density lipoprotein cholesterol, high-density lipoprotein cholesterol (HDL-C), triglyceride (TG), total bilirubin, alanine aminotransferase (ALT), $\gamma$-glutamyl transpeptidase, aspartate aminotransferase (AST), fasting plasma glucose, glycosylated $\mathrm{Hb}$ (HbAlc), 2-h postprandial plasma glucose, fasting insulin, blood urea nitrogen, creatinine (Cr), uric acid (UA), homocysteic acid (HCY) and serum cystatin C (CYSC).

The identification of individuals with MetS was based on the definition of the International Diabetes Federation (35) as follows: i) Central obesity (waist circumference, $\geq 90$ and $\geq 80 \mathrm{~cm}$ in Chinese males and females, respectively); ii) a combination of any of the following four indicators: TG level increased to $>150 \mathrm{mg} / \mathrm{dl}(1.7 \mathrm{mmol} / \mathrm{l})$, or treated accordingly; HDL-C level decreased to $<40 \mathrm{mg} / \mathrm{dl}(0.9 \mathrm{mmol} / \mathrm{l})$ in males and $<50 \mathrm{mg} / \mathrm{dl}(1.1 \mathrm{mmol} / \mathrm{l})$ in females, or the patient receiving corresponding treatment; systolic blood pressure $\geq 130$ or diastolic blood pressure $\geq 85 \mathrm{mmHg}$, or treated accordingly, or previous diagnosis of hypertension; and fasting plasma glucose level increased to $\geq 100 \mathrm{mg} / \mathrm{dl}(5.6 \mathrm{mmol} / \mathrm{l})$, or previous diagnosis of type 2 diabetes mellitus, or the patient receiving corresponding treatment.

IR is generally considered to be the most important pathophysiological basis for MetS. The homeostasis model assessment (HOMA) score may be used to estimate IR, which is defined as follows: [Fasting plasma insulin (mU/l) $\mathrm{x}$ fasting plasma glucose $(\mathrm{mmol} / \mathrm{l})] / 22.5$. A high HOMA-IR score denotes low insulin sensitivity and IR (36). Based on a previous study (17), three cut-off values of the HOMA-IR index $(2,2.5$ and 3) were adopted to evaluate IR.

Statistical analysis. The statistical analysis was performed using IBM-SPSS 24.0.0.0 software (IBM Corp.) and Python. Wilcoxon's rank-sum test was used to evaluate differences between groups for quantitative data, and the Chi-squared test was used for qualitative data. All P-values were based on a two-sided test of statistical significance. $\mathrm{P}<0.05$ was considered to indicate a statistically significant difference. The optimal cut-off point of age was calculated using the maximization of Youden's index (sensitivity+specificity-1) in the receiver operating curve analysis. The association between $H$. pylori status and MetS characteristics was evaluated by a multivariate logistic regression (LR) analysis model following adjustment for age, sex, alcohol consumption, smoking, WBC count, HS-CRP, ALT, AST, HbA1C, HCY, CYSC, Cr and UA levels. The patients were further stratified into subgroups based on age and sex.

\section{Results}

Clinical and demographic characteristics. In the present study, 5,884 participants were included after screening of a total of 10,602 subjects (Fig. 1). The study subjects had a mean age of $46.81 \pm 10.13$ years and $2,053(34.9 \%)$ were female. A total of $1,265(21.5 \%)$ had MetS, with a different percentage among males and females ( 24.8 vs. $15.3 \%$, respectively; $\mathrm{P}<0.001$ ). In addition, the prevalence of MetS was identified to increase with age, particularly in females.

The overall prevalence of $H$.pylori infection in this cohort was $46 \%$, and it was higher in male compared with female patients (47.1 vs. $43.9 \%$, respectively; $\mathrm{P}=0.023$ ), however, it did not exhibit any differences across different age groups.

A statistically significant difference in the presence of $H$. pylori was observed between subjects with and those without MetS (50.4 vs. $44.8 \%$, respectively; $\mathrm{P}<0.001$; Table I).

Overall, age and sex subgroup analyses for the risk of MetS associated with H. Pylori infection. A multivariate LR model was constructed for predicting MetS by considering the H. pylori infection status and other potential covariates, including sex, age and HOMA-IR. It was observed that $H$. pylori infection was a significant risk factor contributing to the prediction of MetS with a broad-line risk of $1.2(95 \%$ CI: 1.02-1.36, P=0.028; Table II). Subsequently, a receiver operating characteristic curve analysis on age was performed to segment participants, which indicated the age of 50 years as an optimal threshold (i.e., maximizing Youden's index; Table III). It was also used to differentiate the MetS distribution between subjects with or without $H$. pylori infection. Furthermore, A multivariate LR model analyses revealed that 
Table I. Demographic characteristics of subjects with or without MetS.

\begin{tabular}{|c|c|c|c|}
\hline \multirow[b]{2}{*}{ Features } & \multicolumn{2}{|c|}{ MetS } & \multirow[b]{2}{*}{ P-value } \\
\hline & Yes & No & \\
\hline Sex (female $\%)$ & $315(24.9)$ & $1738(32.6)$ & $<0.001$ \\
\hline Age (years) & $50.9 \pm 9.9$ & $46.3 \pm 10.3$ & $<0.001$ \\
\hline Height $(\mathrm{cm})$ & $167.8 \pm 8.0$ & $165.7 \pm 7.8$ & $<0.001$ \\
\hline Weight (kg) & $75.8 \pm 10.5$ & $63.8 \pm 10.2$ & $<0.001$ \\
\hline BMI $\left(\mathrm{kg}^{2} / \mathrm{m}^{2}\right)$ & $26.8 \pm 2.6$ & $23.2 \pm 2.7$ & $<0.001$ \\
\hline Waist (cm) & $94.1 \pm 6.7$ & $82.2 \pm 8.3$ & $<0.001$ \\
\hline WBC (x109/1) & $6.51 \pm 1.6$ & $6.1 \pm 1.6$ & $<0.001$ \\
\hline $\mathrm{Hb}(\mathrm{g} / \mathrm{l})$ & $150.5 \pm 14.5$ & $144.7 \pm 16.1$ & $<0.001$ \\
\hline $\operatorname{PLT}\left(\mathrm{x} 10^{9} / 1\right)$ & $214.0 \pm 55.7$ & $212.5 \pm 53.6$ & 0.390 \\
\hline T-BiL $(\mu \mathrm{mol} / \mathrm{l})$ & $13.7 \pm 5.3$ & $13.7 \pm 5.7$ & 0.790 \\
\hline $\operatorname{ALT}(\mathrm{U} / \mathrm{l})$ & $34.5 \pm 26.99$ & $23.5 \pm 23.1$ & $<0.001$ \\
\hline GGTP (U/1) & $56.8 \pm 54.4$ & $34.0 \pm 38.99$ & $<0.001$ \\
\hline $\operatorname{AST}(\mathrm{U} / 1)$ & $27.0 \pm 12.7$ & $22.9 \pm 13.2$ & $<0.001$ \\
\hline Hs-CRP (mg/l) & $2.1 \pm 3.1$ & $1.2 \pm 2.4$ & $<0.001$ \\
\hline BUN (mmol/l) & $5.3 \pm 1.2$ & $4.98 \pm 1.2$ & $<0.001$ \\
\hline $\mathrm{Cr}(\mathrm{mmol} / \mathrm{l})$ & $65.2 \pm 14.0$ & $63.1 \pm 13.97$ & $<0.001$ \\
\hline $\mathrm{UA}(\mu \mathrm{mol} / \mathrm{l})$ & $387.2 \pm 90.9$ & $336.3 \pm 86.8$ & $<0.001$ \\
\hline $\mathrm{HCY}(\mu \mathrm{mol} / \mathrm{l})$ & $11.2 \pm 5.3$ & $10.5 \pm 5.2$ & $<0.001$ \\
\hline CYS (mg/l) & $0.95 \pm 0.2$ & $0.9 \pm 0.2$ & $<0.001$ \\
\hline $\mathrm{TC}(\mathrm{mmol} / \mathrm{l})$ & $5.2 \pm 1.1$ & $4.9 \pm 0.9$ & $<0.001$ \\
\hline TG (mmol/l) & $2.7 \pm 2.3$ & $1.4 \pm 1.3$ & $<0.001$ \\
\hline $\mathrm{LDL}(\mathrm{mmol} / \mathrm{l})$ & $2.9 \pm 0.8$ & $2.8 \pm 0.7$ & $<0.001$ \\
\hline HDL (mmol/l) & $1.07 \pm 0.3$ & $1.2 \pm 0.3$ & $<0.001$ \\
\hline FBG (mg/dl) & $5.9 \pm 1.7$ & $5.0 \pm 0.8$ & $<0.001$ \\
\hline $\operatorname{HbA1c}(\%)$ & $7.4 \pm 1.1$ & $6.8 \pm 0.7$ & $<0.001$ \\
\hline PBG (mg/dl) & $9.0 \pm 4.1$ & $6.5 \pm 2.5$ & $<0.001$ \\
\hline FINS (pmol/l) & $100.8 \pm 51.9$ & $63.6 \pm 35.9$ & $<0.001$ \\
\hline DBP $(\mathrm{mmHg})$ & $83.4 \pm 10.6$ & $74.3 \pm 11.3$ & $<0.001$ \\
\hline $\mathrm{SBP}(\mathrm{mmHg})$ & $136.7 \pm 16.6$ & $121.6 \pm 16.9$ & $<0.001$ \\
\hline H. pylori infection (\%) & $637(50.4)$ & $2068(44.8)$ & $<0.001$ \\
\hline HOMA-IR & $3.8 \pm 2.3$ & $2.1 \pm 1.5$ & $<0.001$ \\
\hline$>2(\%)$ & $1057(87)$ & $1958(42.8)$ & $<0.001$ \\
\hline$>2.5(\%)$ & $888(71.5)$ & $1180(25.8)$ & $<0.001$ \\
\hline$>3(\%)$ & $711(57.2)$ & $689(15.3)$ & $<0.001$ \\
\hline Carotid atherosclerosis (\%) & $441(37.1)$ & $949(22.8)$ & $<0.001$ \\
\hline Diabetes (\%) & $201(15.9)$ & $174(3.8)$ & $<0.001$ \\
\hline Fatty liver (\%) & $1037(82)$ & $1520(32.9)$ & $<0.001$ \\
\hline Drinking (\%) & $700(55.3)$ & $2055(44.5)$ & $<0.001$ \\
\hline Smoking (\%) & $528(42.1)$ & $1429(30.9)$ & $<0.001$ \\
\hline Hypertension (\%) & $416(32.9)$ & $499(10.8)$ & $<0.001$ \\
\hline Hyperlipidemia (\%) & $70(5.5)$ & $53(1.1)$ & $<0.001$ \\
\hline
\end{tabular}

H. pylori, Helicobacter pylori; MetS, metabolic syndrome; SBP, systolic blood pressure; DBP, diastolic blood pressure; BMI, body mass index; WBC, white blood cell; $\mathrm{Hb}$, hemoglobin; PLT, platelets; T-BiL, total bilirubin; BUN, blood urea nitrogen; $\mathrm{Cr}$, creatinine; UA, uric acid; HCY, homocysteic acid; CYSC, serum cystatin C; ALT, alanine aminotransferase; GGTP, $\gamma$-glutamyltranspeptidase; AST, aspartate aminotransferase; HS-CRP, high-sensitivity C-reactive protein; FPG, fasting blood glucose; PBG, 2-hour postprandial blood glucose; FINS, fasting insulin; HbA1c, glycosylated hemoglobin; HOMA-IR, homeostasis model assessment of insulin resistance; TC, total cholesterol; LDL-C, low-density lipoprotein; HDL-C, high-density lipoprotein; TG, triglyceride.
Table II. LR analysis of MetS risk associated with $H$. pylori and other factors.

\begin{tabular}{lcr}
\hline Variables & OR [95\% CI] & P-value \\
\hline H.pylori infection & $1.21[1.02-1.36]$ & 0.028 \\
HOMA-IR & $2.13[1.98-2.20]$ & $<0.001$ \\
Age (years) & $1.11[1.04-1.16]$ & $<0.001$ \\
Gender & $1.54[1.27-1.75]$ & $<0.001$ \\
\hline
\end{tabular}

H. pylori, Helicobacter pylori; HOMA-IR, homeostasis model assessment of insulin resistance; 95\% CI, 95\% confidence interval; $\mathrm{OR}$, odds ratio.

Table III. Sensitivity, specificity and Youden's index at different age cut-off points.

\begin{tabular}{cccc}
\hline Age & Sensitivity & 1-Specificity & Youden's index \\
\hline 15 & 1 & 1 & 0.000 \\
20 & 0.999 & 0.998 & 0.001 \\
30 & 0.986 & 0.928 & 0.058 \\
40 & 0.846 & 0.699 & 0.147 \\
50 & 0.48 & 0.313 & 0.167 \\
60 & 0.158 & 0.081 & 0.077 \\
70 & 0.024 & 0.011 & 0.013 \\
80 & 0.005 & 0.003 & 0.002 \\
\hline
\end{tabular}

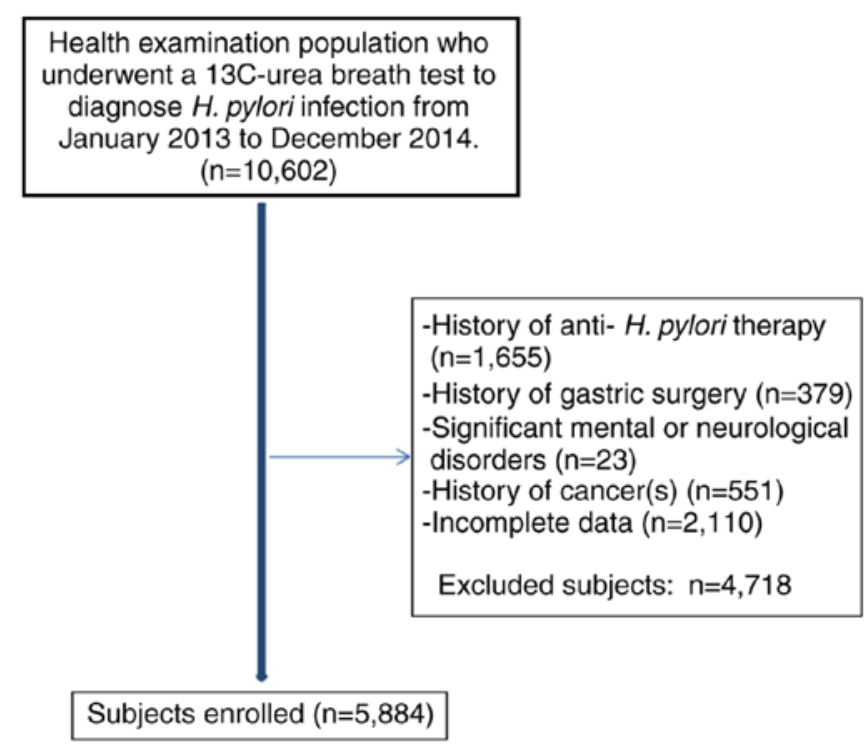

Figure 1. Flow chart depicting the enrolment of subjects in the present study.

H. pylori infection was a significant risk factor for MetS in male participants aged $<50$ years and in female participants aged $\geq 50$ years (Table IV).

Multivariate LR analysis of $H$. pylori infection and other factors with MetS. A multivariate LR analysis was performed to determine the risk of MetS associated with the H. pylori infection status and other metabolic-associated parameters, 
Table IV. LR analysis of the risk of MetS associated with H. pylori infection in different groups.

\begin{tabular}{lcc}
\hline H. pylori groups & OR $[95 \% \mathrm{CI}]$ & P-value \\
\hline $\begin{array}{l}\text { Males } \\
<50 \text { years }\end{array}$ & $1.28[1.04-1.56]$ & 0.017 \\
$\geq 50$ years & $1.21[0.97-1.50]$ & 0.088 \\
Females & & \\
$<50$ years & $0.87[0.58-1.30]$ & 0.495 \\
$\geq 50$ years & $1.53[1.10-2.10]$ & 0.010 \\
\hline
\end{tabular}

H. pylori, Helicobacter pylori; $95 \%$ CI, 95\% confidence interval; OR, odds ratio.

Table V. Predictors of MetS by LR based on H. pylori infection and other factors.

\begin{tabular}{lcr}
\hline Variables & OR $[95 \% \mathrm{CI}]$ & P-value \\
\hline Age (years) & $0.95[0.68-0.98]$ & $<0.001$ \\
Sex & $4.40[4.27-6.97]$ & $<0.001$ \\
HS-CRP $(\mathrm{mg} / \mathrm{l})$ & $1.94[1.80-2.80]$ & $<0.001$ \\
ALT $(\mathrm{U} / \mathrm{l})$ & $0.92[0.85-0.99]$ & $<0.001$ \\
AST $(\mathrm{U} / \mathrm{l})$ & $1.92[1.19-3.15]$ & $<0.001$ \\
HbAlc $(\%)$ & $1.51[1.32-2.92]$ & $<0.001$ \\
Cr $(\mathrm{mmol} / \mathrm{l})$ & $1.01[1.39-1.80]$ & 0.001 \\
UA $(\mu$ mol/l) & $1.99[1.59-3.49]$ & $<0.001$ \\
H. pylori infection & $1.12[1.02-1.59]$ & 0.017 \\
\hline
\end{tabular}

H. pylori, Helicobacter pylori; ALT, alanine aminotransferase; AST, aspartate aminotransferase; HS-CRP, high-sensitivity C-reactive protein; $\mathrm{HbA1c}$, glycosylated hemoglobin; $\mathrm{Cr}$, creatinine; UA, uric acid; 95\% CI, 95\% confidence interval; OR, odds ratio.

which were not direct variables in defining MetS, including WBC count, HS-CRP, ALT, AST, HbAlc, HCY, CYSC, Cr and UA. It was observed that $H$. pylori infection, age, sex, HS-CRP, $\mathrm{HbAlc}$, UA and $\mathrm{Cr}$ were also positively associated with MetS (Table V). When stratifying participants into different gender groups and different age groups, similar patterns among contributors for predicting MetS were revealed. It was noted that, when the subjects were stratified by sex and further by age, $H$. pylori infection was significantly associated with MetS in female patients aged $\geq 50$ years [odds ratio $(\mathrm{OR})=1.29$, $95 \% \mathrm{CI}$ : 1.09-1.91; Table VI].

\section{Discussion}

The present study investigated the prevalence of $H$. pylori infection in subjects with MetS, and further explored the association of $H$. pylori infection and other factors with MetS. A significant difference was identified in the presence of $H$. pylori infection between subjects with and those without MetS (50.4 vs. $44.8 \%$, respectively; $\mathrm{P}<0.001)$. In a multivariate LR analysis, $H$. pylori infection was determined to be significantly associated with MetS in female patients aged $\geq 50$ years.

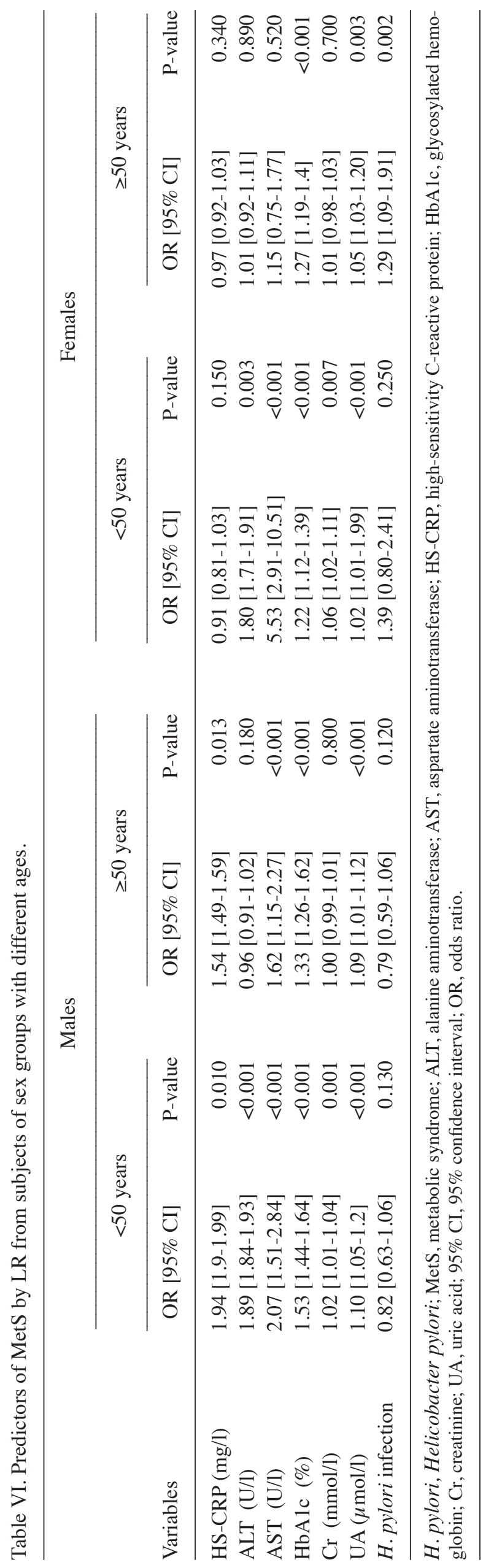


Several studies have identified $H$. pylori infection as a risk factor for MetS (17,20-25). Chen et al (17), reported that the prevalence of MetS was higher among H.pylori-positive individuals of either gender in a Chinese adult cohort. Upala et al (21) demonstrated that $H$. pylori infection was positively associated with IR using a meta-analysis. Yang and Xuan (25) indicated that elderly patients (aged 73.19 \pm 11.03 years) with $H$. pylori infection had a higher BMI and fasting glucose levels and a higher incidence of MetS. Furthermore, certain studies suggested that $H$. pylori infection has a causative association with MetS through pathophysiological analysis (26-28). By contrast, other studies failed to prove this association (29-32). For instance, Naja et al (31) reported no suggested association of $H$. pylori infection with IR or MetS in Lebanese adults. Similarly, Tamura et al (32), identified no association between $H$. pylori infection and diabetes in a Japanese population.

In addition to national and regional factors, these inconsistent results may be due to the different screening methods for H. pylori infection among different studies. H. pylori infection is diagnosed on the basis of clinical and laboratory findings, as well as microbiological and histopathological examinations following endoscopy. Shin et al (37), observed that MetS was more closely associated with histological positivity for H. pylori (adjusted $\mathrm{OR}=1.26$; 95\% CI: 1.08-1.48) rather than serological positivity (adjusted $\mathrm{OR}=1.12,95 \% \mathrm{CI}: 0.95-1.32$ ). This conclusion was attributed to the fact that serological positivity for $H$. pylori does not necessarily indicate current infection. Only few studies have been performed to assess the effects of $H$. pylori infection on MetS in Chinese populations, and most of those are based on the detection of IgG antibody in the serum. Although Chen et al (17) used ${ }^{13} \mathrm{C}$-UBT to demonstrate that $H$. pylori infection is positively associated with MetS, the systemic association among MetS, H. pylori infection and other variables has remained to be elucidated.

In the present study, a different prevalence of $H$. pylori infection was observed between male and female subjects (47.1 vs. $43.9 \%$, respectively; $\mathrm{P}=0.023)$, whereas Chen et al (17) reported a similar prevalence in either gender (20\%) in an adult population from Taiwan. In addition, there was no difference in the prevalence of $H$. pylori infection among different age groups; however, they reported an increase in prevalence with advancing age in males and females (17). Those results indicate a different prevalence (also between the two sexes) of MetS and $H$. pylori infection across the Chinese population, suggesting that different measures have to be taken accordingly. In addition, the present study also observed a difference in the prevalence of MetS between sexes (24.8 vs. $15.3 \%$ in male and female subjects, respectively), consistently with the results of a more recent study (38).

This association was further investigated by stratifying the subjects into males and females, and into different age groups. An increased significance was observed in aged females, which was consistent with a previous study reporting that $H$. pylori infection was a predictor of MetS in elderly patients (aged 73.19 \pm 11.03 years) (25). Although in the present study, $H$. pylori infection was significantly associated with MetS, it was observed that $H$. pylori infection per se was only a weak predictor of MetS (accuracy, 65\%) regardless of sex and age (all these models achieved an accuracy of $\sim 65 \%$ ). Furthermore, H. pylori infection was not the major contributor in the LR model compared with other metabolism-associated parameters, but it may be an important contributor to MetS when combined with other factors. Due to the higher incidence of hyperlipidemia, hyperglycemia or hypertension among individuals aged $>50$ years, $H$. pylori infection has a greater impact in this population. In addition, it has been demonstrated that post-menopausal females have significantly reduced estrogen levels, reduced resistance to inflammatory reactions and increased levels of inflammatory factors $(39,40)$, which may explain for the more pronounced inflammatory response of aged females to $H$. pylori infection compared with males.

The health check-up population at our center mainly comprised residents from Zhejiang province, so the economic level is expected not to differ significantly. In fact, the questionnaire included queries associated with socioeconomic conditions and eating habits. However, a previous statistical analysis indicated that their impact was not significant, so they were not included in the present study.

Of note, the present study had certain limitations. First, the subjects were recruited from a single center. Second, the present study was an observational study, and conclusions may only be drawn regarding the association between $H$. pylori infection and other factors with MetS.

In conclusion, H. pylori infection increases the risk of MetS in aged females. However, these observations are inconsistent across different cohorts, which warrants further investigation by prospective or biochemical studies. If confirmed, eradication of $H$. pylori infection may be of therapeutic value for MetS.

\section{Acknowledgements}

The authors would like to thank Dr Bin Ju (Department of Epidemiology of Zhejiang University) for his advice regarding statistics throughout the project.

\section{Funding}

The present study was supported by the Zhejiang Provincial Natural Science Foundation of China (grant no. LGF19H030016), the Education Department of Zhejiang Province (grant no. Y201636053), and the Zhejiang Provincial Medical Scientific and Technological Projects (grant nos. 2017KY387 and 2018KY413).

\section{Availability of data and materials}

All the datasets generated and analyzed in the present study are included in this published article.

\section{Authors' contributions}

YY and JC contributed to the literature search and the writing of the manuscript; JW and LW contributed to data collection and analysis; ZS designed the study.

\section{Ethics approval and consent to participate}

All of the participants provided written informed consent prior to the examination. The present study was reviewed and approved by the Ethics Committee of the 2nd Affiliated 
Hospital, School of Medicine, Zhejiang University (Hangzhou, China; no. 2013-218).

\section{Patient consent for publication}

Not applicable.

\section{Competing interests}

The authors declare no potential conflicts of interest with respect to the research, authorship and/or publication of this article.

\section{References}

1. Samson SL and Garber AJ: Metabolic syndrome. Endocrinol Metab Clin North Am 43: 1-23, 2014.

2. Giudice A, Crispo A, Massimiliano G, D'Arena G, Tecce MF, Grimaldi M, Amore A, Esposito E and Montella M: Metabolic syndrome, insulin resistance, circadian disruption, antioxidants and pancreatic carcinoma: An overview. J Gastrointestin Liver Dis 23: 73-77, 2014

3. Hoffman EL, VonWald T and Hansen K: The metabolic syndrome. S D Med 9: 24-28, 2015.

4. Festa A, D'Agostino R Jr, Howard G, Mykkänen L, Tracy RP and Haffner SM: Chronic subclinical inflammation as part of the insulin resistance syndrome: The insulin resistance atherosclerosis study (IRAS). Circulation 102: 42-47, 2000.

5. Suerbaum S and Michetti P: Helicobacter pylori infection. N Engl J Med 347: 1175-1186, 2002.

6. McColl KE: Clinical practice. Helicobacter pylori infection. N Engl J Med 362: 1597-1604, 2010.

7. Qadri Q, Rasool R, Gulzar GM, Naqash S and Shah ZA: H. pylori infection, inflammation and gastric cancer. J Gastrointest Cancer 45: 126-132, 2014.

8. Atherton JC: The pathogenesis of Helicobacter pylori-induced gastro-duodenal diseases. Annu Rev Pathol 1: 63-96, 2006.

9. Lee YC, Chen TH, Chiu HM, Shun CT, Chiang H, Liu TY, Wu MS and Lin JT: The benefit of mass eradication of Helicobacter pylori infection: A community-based study of gastric cancer prevention. Gut 62: 676-682, 2013.

10. Malfertheiner P, Megraud F, O'Morain CA,Gisbert JP, Kuipers EJ, Axon AT, Bazzoli F, Gasbarrini A, Atherton J, Graham DY, et al: Management of Helicobacter pylori infection-the Maastricht V/Florence Consensus Report. Gut 66: 6-30, 2017.

11. Oshima T, Ozono R, Yano Y, Oishi Y, Teragawa H, Higashi Y, Yoshizumi M and Kambe M: Association of Helicobacter pylori infection with systemic inflammation and endothelial dysfunction in healthy male subjects. J Am Coll Cardiol 45: 1219-1222, 2005.

12. Franceschi F, Annalisa T, Teresa DR, Giovanna D, Ianiro G, Franco S, Viviana G, Valentina T, Riccardo LL and Antonio G: Role of Helicobacter pylori infection on nutrition and metabolism. World J Gastroenterol 20: 12809-12817, 2014.

13. Kyburz A and Muller A: Helicobacter pylori and extragastric diseases. Curr Top Microbiol Immunol 400: 325-347, 2017.

14. Goni E and Franceschi F: Helicobacter pylori and extragastric diseases. Helicobacter 21 (Suppl 1): S45-S48, 2016.

15. Albaker WI: Helicobacter pylori infection and its relationship to metabolic syndrome: Is it a myth or fact? Saudi J Gastroenterol 17: 165-169, 2011.

16. Chen LW, Chien CY, Yang KJ, Kuo SF, Chen CH and Chien RN: Helicobacter pylori infection increases insulin resistance and metabolic syndrome in residents younger than 50 years old: A community-based study. PLoS One 10: e0128671, 2015.

17. Chen TP, Hung HF, Chen MK, Lai HH, Hsu WF, Huang KC and Yang KC: Helicobacter pylori infection is positively associated with metabolic syndrome in taiwanese adults: A cross-sectional study. Helicobacter 20: 184-191, 2015.

18. Işıktaş Sayılar E, Çelik B and Dumlu Ş: Relationship between Helicobacter pylori infection and metabolic syndrome. Turk J Gastroenterol 26: 468-473, 2015.

19. Koklu H, Koklu S and Cinar H: Helicobacter pylori and metabolic syndrome. Turk J Gastroenterol 27: 201, 2016.

20. Vafaeimanesh J, Bagherzadeh M, Mirzaei A, Parham M, Norouzinia $M$ and Vafaee R: Effect of Helicobacter pylori on metabolic syndrome parameters in diabetic patients. Gastroenterol Hepatol Bed Bench 9 (Suppl 1): S36-S41, 2016.
21. Upala S, Jaruvongvanich V, Riangwiwat T, Jaruvongvanich S and Sanguankeo A: Association between Helicobacter pylori infection and metabolic syndrome: A systematic review and meta-analysis. J Dig Dis 17: 433-440, 2016.

22. Polyzos SA and Kountouras J: Novel advances in the association between helicobacter pylori infection, metabolic syndrome, and related morbidity. Helicobacter 20: 405-409, 2015.

23. Kayar Y, Pamukçu Ö, Eroğlu H, Kalkan Erol K, Ilhan A and Kocaman O: Relationship between Helicobacter pylori infections in diabetic patients and inflammations, metabolic syndrome, and complications. Int J Chronic Dis 2015: 290128, 2015.

24. Lu LJ, Hao NB, Liu JJ, Li X and Wang RL: Correlation between Helicobacter pylori infection and metabolic abnormality in general population: A cross-sectional study. Gastroenterol Res Pract 2018: $7410801,2018$.

25. Yang W and Xuan C: Influence of Helicobacter pylori infection on metabolic syndrome in old chinese people. Gastroenterol Res Pract 2016: 6951264, 2016.

26. Ando $\mathrm{T}$, Ishikawa $\mathrm{T}$, Takagi $\mathrm{T}$, Imamoto $\mathrm{E}$, Kishimoto $\mathrm{E}$, Okajima A, Uchiyama K, Handa O, Yagi N, Kokura S, et al: Impact of Helicobacter pylori eradication on circulating adiponectin in humans. Helicobacter 18: 158-164, 2013.

27. de Luis DA, Garcia Avello A, Lasuncion MA, Aller R, Martin de Argila C, Boixeda de Miquel D and de la Calle H: Improvement in lipid and haemostasis patterns after Helicobacter pylori infection eradication in type 1 diabetic patients. Clin Nutr 18: 227-231, 1999.

28. Gen R, Demir M and Ataseven H: Effect of Helicobacter pylori eradication on insulin resistance, serum lipids and low-grade inflammation. South Med J 103: 190-196, 2010.

29. Devaraj S, Rosenson RS and Jialal I: Metabolic syndrome: An appraisal of the pro-inflammatory and procoagulant status. Endocrinol Metab Clin North Am 33: 431-453, 2004.

30. Gillum RF: Infection with Helicobacter pylori, coronary heart disease, cardiovascular risk factors, and systemic inflammation: The third national health and nutrition examination survey. J Natl Med Assoc 96: 1470-1476, 2004.

31. Naja F, Nasreddine L, Hwalla N, Moghames P, Shoaib H, Fatfat M, Sibai A and Gali-Muhtasib H: Association of $\mathrm{H}$. pylori infection with insulin resistance and metabolic syndrome among lebanese adults. Helicobacter 17: 444-451, 2012.

32. Tamura T, Morita E, Kawai S, Sasakabe T, Sugimoto Y, Fukuda N, Suma S, Nakagawa H, Okada R, Hishida A, et al: No association between Helicobacter pylori infection and diabetes mellitus among a general Japanese population: A cross-sectional study. Springerplus 4: 602,2015.

33. Miernyk KM, Bruden DL, Bruce MG, McMahon BJ, Hennessy TW, Peters HV, Hurlburt DA, Sacco F and Parkinson AJ: Dynamics of Helicobacter pylori-specific immunoglobulin $\mathrm{G}$ for 2 years after successful eradication of Helicobacter pylori infection in an American Indian and Alaska native population. Clin Vaccine Immunol 14: 85-86, 2007.

34. Ferwana M, Abdulmajeed I, Alhajiahmed A, Madani W, Firwana B, Hasan R, Altayar O, Limburg PJ, Murad MH and Knawy B: Accuracy of urea breath test in Helicobacter pylori infection: Meta-analysis. World J Gastroenterol 21: 1305-1314, 2015.

35. Alberti KG, Zimmet P, Shaw J and IDF Epidemiology Task Force Consensus Group: The metabolic syndrome-a new worldwide definition. Lancet 366: 1059-1062, 2005.

36. Gayoso-Diz P, Otero-González A, Rodriguez-Alvarez MX, Gude F, García F, De Francisco A and Quintela AG: Insulin resistance (HOMA-IR) cut-off values and the metabolic syndrome in a general adult population: Effect of gender and age: EPIRCE cross-sectional study. BMC Endocr Disord 13: 47, 2013.

37. Shin DW, Kwon HT, Kang JM, Park JH, Choi HC, Park MS, Park MS, Park SM, Son KY and Cho B: Association between metabolic syndrome and Helicobacter pylori infection diagnosed by histologic status and serological status. J Clin Gastroenterol 46: 840-845, 2012.

38. Refaeli R, Chodick G, Haj S, Goren S, Shalev V and Muhsen K: Relationships of $\mathrm{H}$. pylori infection and its related gastroduodenal morbidity with metabolic syndrome: A large cross-sectional study. Sci Rep 8: 4088, 2018.

39. Figueroa-Vega N, Moreno-Frías C and Malacara JM: Alterations in adhesion molecules, pro-inflammatory cytokines and cell-derived microparticles contribute to intima-media thickness and symptoms in postmenopausal women. PLoS One 10: e0120990, 2015.

40. Taleb-Belkadi O, Chaib H, Zemour L, Fatah A, Chafi B and Mekki K: Lipid profile, inflammation, and oxidative status in periand postmenopausal women. Gynecol Endocrinol 32: 982-985, 2016.

This work is licensed under a Creative Commons Attribution-NonCommercial-NoDerivatives 4.0 International (CC BY-NC-ND 4.0) License. 